\title{
In Vitro Hepatic Uptake in Human and Monkey Hepatocytes in the Presence and Absence of Serum Protein and Its In Vitro to In Vivo Extrapolation ${ }^{\mathbb{}}$
}

\author{
Xiaomin Liang, Yeojin Park, Natalie DeForest, Jia Hao, Xiaofeng Zhao, Congrong Niu, Kelly Wang, \\ Bill Smith, and (1) Yurong Lai
}

Drug Metabolism, Gilead Sciences Inc., Foster City, California

Received June 27, 2020; accepted September 28, 2020

\begin{abstract}
It is well documented that human hepatic clearance based on in vitro metabolism or transporter assays systematically resulted in underprediction; therefore, large empirical scalars are often needed in either static or physiologically based pharmacokinetic (PBPK) models to accurately predict human pharmacokinetics (PK). In our current investigation, we assessed hepatic uptake in hepatocyte suspension in Krebs-Henseleit buffer in the presence and absence of serum. The results showed that the unbound intrinsic active clearance $\left(\mathrm{CL}_{\mathrm{u} \text {,int,active }}\right)$ values obtained by normalizing the unbound fraction in the buffer containing $10 \%$ serum were generally higher

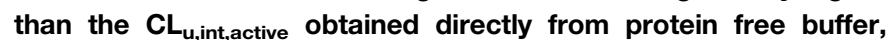
suggesting "protein-facilitated" uptake. The differences of $C L_{u, i n t, a c-}$ tive in the buffer with and without protein ranged from 1- to 925-fold and negatively correlated to the unbound serum binding of organic anion transporting polypeptide substrates. When using the uptake values obtained from buffer containing serum versus serum-free buffer, the median of scaling factors (SFs) for $\mathrm{CL}_{\mathrm{u} \text {,int,active }}$ reduced from 24.2-4.6 to 22.7-7.1 for human and monkey, respectively, demonstrating the improvement of in vitro to in vivo extrapolation in a PBPK model. Furthermore, values of $\mathrm{CL}_{\mathrm{u} \text {,int,active }}$ were significantly
\end{abstract}

higher in monkey hepatocytes than that in human, and the species differences appeared to be compound dependent. Scaling up in vitro uptake values derived in assays containing species-specific serum can compensate for the species-specific variabilities when using cynomolgus monkey as a probe animal model. Incorporating SFs calibrated in monkey and together with scaled in vitro data can be a reliable approach for the prospective human PK prediction in early drug discovery.

\section{SIGNIFICANCE STATEMENT}

We investigated the protein effect on hepatic uptake in human and monkey hepatocytes and improved the in vitro to in vivo extrapolation using parameters obtained from the incubation in the present of serum protein. In addition, significantly higher active uptake clearances were observed in monkey hepatocytes than in human, and the species differences appeared to be compound dependent. The physiologically based pharmacokinetic model that incorporates scaling factors calibrated in monkey and together with scaled in vitro human data can be a reliable approach for the prospective human pharmacokinetics prediction.

\section{Introduction}

Accurately predicting hepatic clearance is essential for ranking and optimizing new chemical entities in the current drug discovery and development practices; furthermore, it is critically needed for understanding potential oral bioavailability, evaluating drug-drug interactions (DDIs), and determining doses in first-in-man trials. As systemic clearance $(\mathrm{CL})$ is a fundamental pharmacokinetic $(\mathrm{PK})$ parameter for human dose projection, discovery of bioavailable and metabolically stable small molecule drug candidates are ideal goals in early PK optimization. Prediction of systemic clearance for drug candidates by major elimination organ liver is more involved. Over the past two decades, many empirical and physiologically based approaches have

https://doi.org/10.1124/dmd.120.000163.

S This article has supplemental material available at dmd.aspetjournals.org. been developed for human CL prediction (Ito and Houston, 2005; Chiba et al., 2009). For example, in vitro metabolic stability assays using liver derived systems such as liver microsomes, cytosols, and hepatocytes are routinely used for assessing enzyme stability in the early discovery stage as a high-throughput tool to select metabolically stable molecules in pharmaceutical companies (Obach et al., 1997). The rationale of these approaches is that the liver preparations prepared from human or preclinical species can reserve the enzyme activities and should reasonably represent in vivo clearance.

Recently, increasing recognition was given to transporter-mediated clearance in the role of affecting drug bioavailability (first-pass hepatic extraction) and elimination. Many pharmacogenomics and DDI studies in organic anion transporting polypeptide (OATP) substrates showed transporter-mediated clearance affecting systemic drug exposure (Lai et al., 2010, 2012; El-Kattan et al., 2016; Yee et al., 2018). Incorporating transporter-mediated CL in the prediction of overall hepatic CL, also

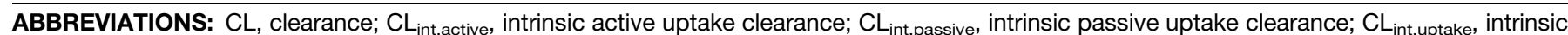

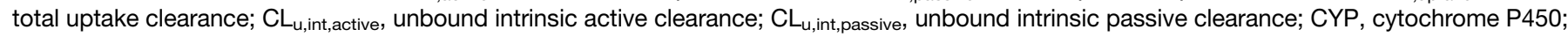
$\mathrm{DDI}$, drug-drug interaction; fu, unbound fraction; IVIVE, in vitro to in vivo extrapolation; KHB, Krebs-Henseleit buffer; LC-MS/MS, liquid chromatography-tandem mass spectrometry; OATP, organic anion transporting polypeptide; PBPK, physiologically based pharmacokinetics; PK, pharmacokinetics; SF, scaling factor. 
known as the extended clearance concept, was first introduced by Sirianni and Pang and was extensively investigated by other research groups (Sirianni and Pang, 1997; Kunze et al., 2015; Patilea-Vrana and Unadkat, 2016; Benet et al., 2018). Currently, a range of in vitro tools with increasing sophistication of transporter expressions are used to characterize transporter-mediated CL parameters for human PK prediction. Among the in vitro systems, hepatocytes with expression of transporter and enzyme proteins that mimic in vivo are often preferred to estimate in vitro hepatic uptake CL in suspended, plated, and sandwichcultured hepatocytes formats. However, the discrepancies in in vitro to in vivo extrapolation (IVIVE), e.g., underpredicting in vivo hepatic uptake CL, are concerns that merited further investigations (Jones et al., 2012; Barton et al., 2013). Commonly large empirical scaling factors (SFs) were applied for transporter-mediated CL to fit in vivo human PK (Jones et al., 2012). The need of large empirical SFs for IVIVE also holds true in preclinical species (Watanabe et al., 2009; Morse et al., 2017; De Bruyn et al., 2018). The SFs appeared to be compound dependent, and the highly protein-bound compounds tended to have larger SFs (Jones et al., 2012; Morse et al., 2017; De Bruyn et al., 2018). Over the past years, various efforts have been made to reduce the IVIVE SFs through optimizing in vitro methodologies, for example, to measure the difference of transporter expressions between in vitro and in vivo ( $\mathrm{Li}$ et al., 2010), to incorporate human serum protein (Bowman et al., 2019; Kim et al., 2019), and to establish a "universal" SF from an internal/local in vitro system for laboratory specific parameters (De Bruyn et al., 2018). In our current investigation, hepatic uptake assays were conducted in suspension human and monkey hepatocytes in the presence or absence of their respective serum to elucidate the impact of protein on the active uptake for known OATP substrates. Species differences of intrinsic total uptake clearance $\left(\mathrm{CL}_{\text {int,uptake }}\right)$ between human and monkey hepatocytes were also evaluated in the presence of serum protein. Additionally, a physiologically based pharmacokinetic (PBPK) model was developed to obtain SFs from the IVIVE in monkey and human. Our comprehensive investigation on species differences in hepatic uptake for 15 OATP substrates provided insightful information for the future usage of cynomolgus monkey as a probe animal model for SFs to predict human PK. Furthermore, the extensive analysis of IVIVE using compounds with a broader range of protein binding demonstrated the need for incorporating the protein-facilitated uptake for the human PK prediction.

\section{Materials and Methods}

Materials. Pitavastatin calcium was purchased from Fisher Scientific Company, LLC (Pittsburgh, PA). Bosentan hydrate, danoprevir, labetolol, repaglinide, valsartan, maraviroc, telmisartan, cerivastatin sodium, fluvastatin sodium, pravastatin sodium, atorvastatin calcium, rosuvastatin calcium, bucetin, warfarin, silicone oil, and mineral oil were purchased from Sigma-Aldrich, Inc. (St. Louis, MO). Grazoprevir was purchased from American Radiolabeled Chemicals, Inc. (St. Louis, MO). Sorafenib was purchased from Selleck Chemicals (Houston, TX). Asunaprevir were synthesized in house. Cryopreserved human (lots XPM, YTW, and PZA) (Supplemental Table 1), cynomolgus monkey (lots PNC, VNV, and UHK) hepatocytes (Supplemental Table 2), In VitroGRO HT medium, and Krebs-Henseleit buffer (KHB) were obtained from BioIVT (Hicksville, NY). Cynomolgus monkey serum was purchased from Innovative Research Inc. (Novi, MI). Human serum was obtained from Corning Inc. (Corning, NY).

Hepatic Uptake Studies in Cryopreserved Human and Cynomolgus Monkey Hepatocytes. A total of 15 known OATP substrates were selected for the hepatic uptake assays. The in vitro hepatic uptake clearance was evaluated in three different lots of hepatocytes for each species at a single concentration. Besides repaglinide (dosed at $0.1 \mu \mathrm{M}$ ), another 14 compounds were dosed at $1 \mu \mathrm{M}$ in this study. Human hepatocyte lot XPM and monkey hepatocyte lot UHK were used in experiments to assess the impact of serum protein on hepatic uptake.
Uptake studies were conducted in suspended hepatocytes using the oil-spin method as previously described (Kimoto et al., 2011; Morse et al., 2015). In brief, cryopreserved hepatocytes were thawed at $37^{\circ} \mathrm{C}$ and immediately suspended in In VitroGro-HT medium. The hepatocytes were centrifuged at $50 \mathrm{~g}$ for 4 minutes at $4^{\circ} \mathrm{C}$. After centrifuging, the cells were gently resuspended in ice-cold $\mathrm{KHB}$ buffer. Cell viability was determined by trypan blue staining. The cell viability of hepatocyte lots used in this study exceeded $80 \%$. The hepatocytes were diluted to 2 million cells/ml in KHB with $10 \%$ (v/v) human and cynomolgus monkey serum, respectively. The compounds $(1000 \times$ concentration in DMSO) were diluted in uptake buffer (KHB with or without $10 \%$ human or cynomolgus monkey serum). Prior to uptake experiments, cell suspension and uptake buffer containing $2 \times$ substrate concentration was incubated at warm or ice-cold water bath for 10 minutes to reach the uptake temperature at $37^{\circ} \mathrm{C}$ or $4^{\circ} \mathrm{C}$. Uptake assays were initiated by adding the uptake buffer to cell suspension ( $1: 1 \mathrm{in} \mathrm{v} / \mathrm{v})$, which resulted in $1 \times$ final substrate concentration in a cell density of 1 million cells $/ \mathrm{ml}$. For the uptake studies, all compounds were performed in $1 \mu \mathrm{M}$ final concentration, except repaglinide, which had a final concentration of $0.1 \mu \mathrm{M}$. The incubations were terminated at $0.25,0.5,1,1.5$, and 5 minutes by collecting $100 \mu \mathrm{l}$ of incubation mixture onto a microcentrifuge tube containing two layers preloaded. The bottom layer contained $100 \mu \mathrm{l}$ of $3 \mathrm{M}$ ammonium acetate, and the upper layer contained $100 \mu \mathrm{l}$ oil mixture of silicone oil and mineral oil (density $=1.015)$. The microcentrifuge tubes were immediately centrifuged at $14,000 \mathrm{rpm}$ for 14 seconds in Eppendorf benchtop centrifuge. The oil layer separated the cells from the uptake buffer. Microcentrifuge tubes were immediately placed on dry ice and transferred to $-80^{\circ} \mathrm{C}$ freezer until analysis. The active transporter-mediated uptake was assessed at $37^{\circ} \mathrm{C}$, and passive diffusion was assessed at $4^{\circ} \mathrm{C}$, assuming minimal transporter activities at $4^{\circ} \mathrm{C}$. For each batch of uptake experiment, rosuvastatin was included to monitor variations from batch to batch. The uptake assay was conducted in triplicates at each time point for all compounds. Human hepatocyte lot XPM and monkey hepatocyte lot UHK were used in the uptake study to compare the in vitro hepatic uptake clearance in the presence or absence of serum protein. Moreover, three donors of human (XPM, PZA, and YTW) and monkey (UHK, PNC, and VNV) hepatocytes were used to further assess the donor variability.

Liquid Chromatography-Tandem Mass Spectroscopy Analysis. Tips of microcentrifuge tubes containing hepatocyte pellets were cut and placed upside down in deep 96 well plates. One hundred microliters of deionized water was added to each well, and the cells were sonicated for 10 minutes. Two hundred microliters of $100 \%$ acetonitrile with internal standard, labetalol, was added to the wells for compound extraction. The samples were sonicated for 10 minutes, followed by shaking on a shaker for 20 minutes. After additional 5 minutes sonication, the samples were centrifuged at $4000 \mathrm{rpm}$ for 20 minutes at $4^{\circ} \mathrm{C}$. Standard curves for quantitation were prepared in blank hepatocyte pellets that were treated similarly to hepatocyte samples. One hundred fifty microliters aliquot was transferred into 96 deep-well plates and then completely dried. The samples were reconstituted in $200 \mu \mathrm{l}$ buffer containing $20 \%$ acetonitrile and $80 \%$ water with $0.1 \%$ formic acid. The samples were vortexed and centrifuged at $3500 \mathrm{rpm}$ at $4^{\circ} \mathrm{C}$ for 20 minutes before liquid chromatography-tandem mass spectrometry (LC-MS/MS) analysis.

All the samples were analyzed on a Sciex Qtrap 6500 LC-MS/MS (Redwood City, CA) coupled with a Shimadzu Nexera-X2 ultra-high-performance liquid chromatograph (Shimadzu Corporation, Kyoto, Japan). Ten microliters of the sample were injected onto a Waters Acquity UPLC BEH C18 column (1.7 $\mu \mathrm{m}$, $2.1 \times 50 \mathrm{~mm}$ ) (Milford, MA) and eluted by gradient mobile phases of $0.1 \%$ formic acid in water (A) and acetonitrile (B). The LC-MS/MS conditions for each compound are summarized in Supplemental Table 3.

Unbound Fraction in Serum Protein. Serum protein binding of 15 compounds was determined in $100 \%$ and $10 \%$ human or monkey serum by equilibrium dialysis with a Rapid Equilibrium Dialysis Device (Thermo Fisher Scientific, Rockford, IL). The DMSO stock solution of the test article was spiked into $100 \%$ or $10 \%$ (diluted in KHB buffer) human or monkey serum to a final concentration of $2 \mu \mathrm{M}$. One hundred microliters aliquot of the spiked serum was transferred to a 96-well deep-well plate as the T0 sample. Blank KHB buffer (pH $7.4,100 \mu \mathrm{l})$ was added to the plate to make the matrix of 50:50 (v/v) serum:buffer. The T0 samples were incubated at $37^{\circ} \mathrm{C}$ for 4 hours. The spiked samples were placed into the sample chamber $(300 \mu \mathrm{l})$, and the KHB buffer was placed into the adjacent buffer chamber $(500 \mu \mathrm{l})$. The plate was sealed with a self-adhesive lid and incubated at $37^{\circ} \mathrm{C}$ on an orbital shaker $(250 \mathrm{rpm})$ for 4 hours. The assay was 
carried in duplicates. At the end of the incubations, aliquots $(100 \mu 1)$ were taken from both the serum and buffer chambers. Blank KHB buffer $(100 \mu l)$ was added to the serum samples, and blank serum or $10 \%$ serum $(100 \mu \mathrm{l})$ were added to the buffer samples. Finally, $300 \mu \mathrm{l}$ of quench solution (50\% acetonitrile and $50 \%$ methanol with $0.05 \%$ formic acid) containing internal standards (bucetin and warfarin) was added to each sample. The quenched samples were vortexed vigorously for 20 minutes and centrifuged at $4000 \mathrm{rpm}$ at $10^{\circ} \mathrm{C}$. The supernatants were transferred to a 96-well plate and analyzed by LC-MS/MS. The percentage free and percentage recovery of the test compound were calculated (Supplemental Table 4).

In Vitro Uptake Data Analysis. The $\mathrm{CL}_{\text {int,uptake }}$ and intrinsic passive uptake clearance $\left(\mathrm{CL}_{\text {int,passive }}\right)$ were obtained from the initial uptake rates at $37^{\circ} \mathrm{C}$ or $4^{\circ} \mathrm{C}$, respectively. The initial uptake rates were estimated from the slopes of linear uptake phase using linear regression analysis. The intrinsic uptake clearance values were calculated by dividing the initial uptake velocity by the nominal substrate concentration. The intrinsic active uptake clearance $\left(\mathrm{CL}_{\text {int, active }}\right)$ was calculated by subtracting the $\mathrm{CL}_{\text {int,passive }}$ from $\mathrm{CL}_{\text {int,uptake. The unbound intrinsic }}$ uptake clearance [unbound intrinsic active clearance $\left(\mathrm{CL}_{\mathrm{u}, \text { int,active }}\right)$ and unbound intrinsic passive clearance $\left.\left(\mathrm{CL}_{\mathrm{u} \text {,int,passive }}\right)\right]$ was calculated by dividing intrinsic clearance by the measured unbound fraction in buffer containing $10 \%$ serum or $100 \%$ for study in serum free buffer.

The in vitro intrinsic CL values were expressed as microliters per minute per million cells. The scaled in vivo intrinsic clearances were calculated by multiplying hepatocellularity (125 million cells/g liver in human and 122 million cells/g liver in cynomolgus monkey) and liver weight of 25.5 and $19.7 \mathrm{~g}$ liver $/ \mathrm{kg}$ body weight in human and cynomolgus monkey, respectively. The numbers of hepatocellularity and liver weight were adapted from SimCYP (version 17; Certara Ltd.).

In Vivo Pharmacokinetic Study of Pitavastatin in Cynomolgus Monkey. PK studies were performed in cynomolgus monkeys to understand IVIVE of in vitro hepatic uptake parameters. The PK studies were performed in WuXi AppTec (Suzhou, China). All procedures were approved by an Institutional Animal Care and Use Committee. In brief, each cynomolgus monkey ( $n=4$ male, $3-5 \mathrm{~kg}$ ) was dosed at $0.5 \mathrm{mg} / \mathrm{kg}$ in $5 \%$ DMSO/95\% saline solution. Individual doses were calculated based on body weights recorded on the day of dose administration. The intravenous dose was administered as an approximately 30minute infusion using a calibrated Harvard Apparatus PHD 2000 infusion pump via cephalic vein. Serial blood samples were collected via the femoral vein before dosing and at predefined time points. Blood samples were maintained on ice prior to centrifugation to obtain plasma $\left(\mathrm{K}_{2}\right.$ EDTA). Centrifugation began within 1 hour of collection. Plasma samples (approximately $500 \mu \mathrm{l}$ ) were placed into a 96-well tube containing $4 \mu \mathrm{l}$ of formic acid (the final concentration of formic acid in plasma was approximately $2 \%$ ), and samples were vortex mixed. The plasma samples were analyzed using LC-MS/MS.

Physiologically Based Pharmacokinetic Model Analysis for In Vivo Hepatic Uptake Parameters. A five-compartmental liver model was adapted from previously published PBPK model for OATP substrates (Jones et al., 2012; Morse et al., 2015, 2017). The mass balance differential equations described previously (Jones et al., 2012; Morse et al., 2017) were employed in SAAM II (Epsilon Group, Charlottesville, VA). The tissue partition coefficient (Kp) for each nonliver tissue was obtained from SimCYP (version 17; Certara Ltd.). A fitting procedure for pitavastatin plasma PK curves was performed to determine in vivo hepatic clearance parameters, using a similar procedure previously published for other OATP substrates (Jones et al., 2012; Morse et al., 2017). In brief, the scaled unbound intrinsic CL parameters calculated from the in vitro uptake values obtained from uptake assay using the protein free buffer or buffer containing $10 \%$ serum were used as the initial estimates. The fitted values of $\mathrm{CL}_{\mathrm{u} \text {,int,active }}, \mathrm{CL}_{\mathrm{u}}$,int,passive, and unbound intrinsic biliary clearance $\left(\mathrm{CL}_{\mathrm{u}}\right.$,int,bile $)$ were estimated by fitting the plasma PK curve. The pitavastatin monkey plasma PK data were obtained from in-house data, and the human plasma PK data were digitalized (GetData Graph Digitizer V 2.26.0) from previously published New Drug Application (NDA022363). The empirical SFs were calculated for each of

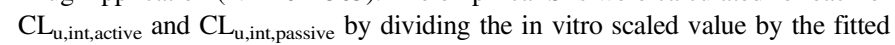
value. The median of SFs across the drugs in the data set was calculated.

\section{Results}

In Vitro Hepatic Uptake in Human and Monkey Hepatocytes in Presence or Absence of Serum Protein. The impact of serum protein on the hepatic uptake was first assessed in in suspension human and monkey hepatocytes. The hepatocytes were incubated with known OATP substrates in KHB buffer with or without $10 \%$ serum. The unbound serum protein fraction of OATP substrates in both $100 \%$ and $10 \%$ serum buffer was measured, and data are summarized in Supplemental Table 4. All compounds had good recovery numbers $(>80 \%)$. Because sorafenib is highly bound to serum protein, the percentage free in $100 \%$ human or monkey serum could not be determined. Among these OATP substrates, the serum protein binding values were highly correlated between human and monkey, as $R^{2}$ values were higher than 0.9 in both assays measured in $100 \%$ serum and $10 \%$ serum containing buffer (Fig. 1). The in vitro values of unbound intrinsic uptake clearance $\left(\mathrm{CL}_{\mathrm{u} \text {,int,uptake }}\right), \mathrm{CL}_{\mathrm{u} \text {,int,active }}$, and $\mathrm{CL}_{\mathrm{u} \text {,int,passive }}$ for 15 OATP substrates obtained from incubation with and without serum protein are summarized in Table 1. As shown in Table 1 , the values of $\mathrm{CL}_{\mathrm{u} \text {,int,active }}$ obtained in the buffer containing $10 \%$ serum protein were generally higher than values obtained directly from the uptake in the protein free buffer in both human and monkey hepatic uptake studies. The shift ranged from 1.5- to 924.6-fold higher in human or 1- to 878.5-fold higher in monkey, respectively. The higher fold differences were observed in higher serum protein bound compounds. In additional, a similar trend of shift was observed in $\mathrm{CL}_{\mathrm{u} \text {,int,passive }}$ for highly protein bound compounds. Similar observations were reported in recent publicationss from other research groups (Bowman et al., 2019, 2020; Kim et al., 2019). In the nonparametric Spearman correlation test, the fold differences of $\mathrm{CL}_{\mathrm{u} \text {,int,passive }}$ and $\mathrm{CL}_{\mathrm{u} \text {,int,active }}$ in both human (Fig. 2, A and B) and monkey hepatocytes (Fig. 2, C and D) were negatively correlated with the serum protein binding values.

In Vitro to In Vivo Extrapolation of Hepatic Uptake Clearances in PBPK Modeling. Recent publications suggested that performing in vitro hepatic uptake studies in the presence of protein could improve the prediction of transporter-mediated hepatic clearance (Bowman et al., 2019; Kim et al., 2019). In our current study, the impact of addition of serum protein in the uptake assay on the improvement of IVIVE was further investigated in PBPK modeling. The in vivo intrinsic CL fitted parameters were estimated by human or monkey PBPK models reported previously (Jones et al., 2012; Morse et al., 2015, 2017), except for pitavastatin. The IVIVE of pitavastatin in monkey and human was performed by a curve fit of plasma PK using in-house PBPK model adapted from previously published models (Jones et al., 2012; Morse et al., 2017) (Fig. 3). As shown in Table 2, the SFs for $\mathrm{CL}_{\mathrm{u} \text {,int,passive }}$ ranged from 0.1 to 7.7 with the median of 0.8 in human or the median of 0.9 in monkey when using the scaled in vitro parameters obtained from the incubation without serum protein, whereas the SFs ranged from 0.1 to 10.3 with the median of 0.5 in human or the median of 0.6 in monkey when applying the in vitro parameters from the incubation with $10 \%$ serum. On the other hand,

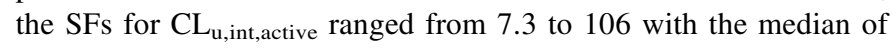
24.2 in human or 22.7 in monkey when in vitro parameters were acquired from the incubation in serum free buffer. As expected, the

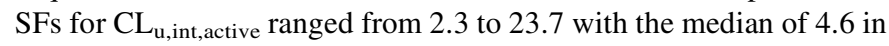
human or 7.1 in monkey when the model incorporated the scaled in vitro parameters obtained from the incubation in buffer containing $10 \%$ serum. The results indicated that the empirical SFs were significantly larger when using in vitro parameters obtained in the serum free buffer, as compared with the parameters obtained from the incubation with serum protein added.

Differences of Hepatic Uptake Clearance in Human and Monkey Hepatocytes for Known OATP Substrates. To assess the species differences and donor variability in transporter-mediated uptake in hepatocytes between human and cynomolgus monkey, hepatic uptake assays were conducted in two additional donors for each species. The 

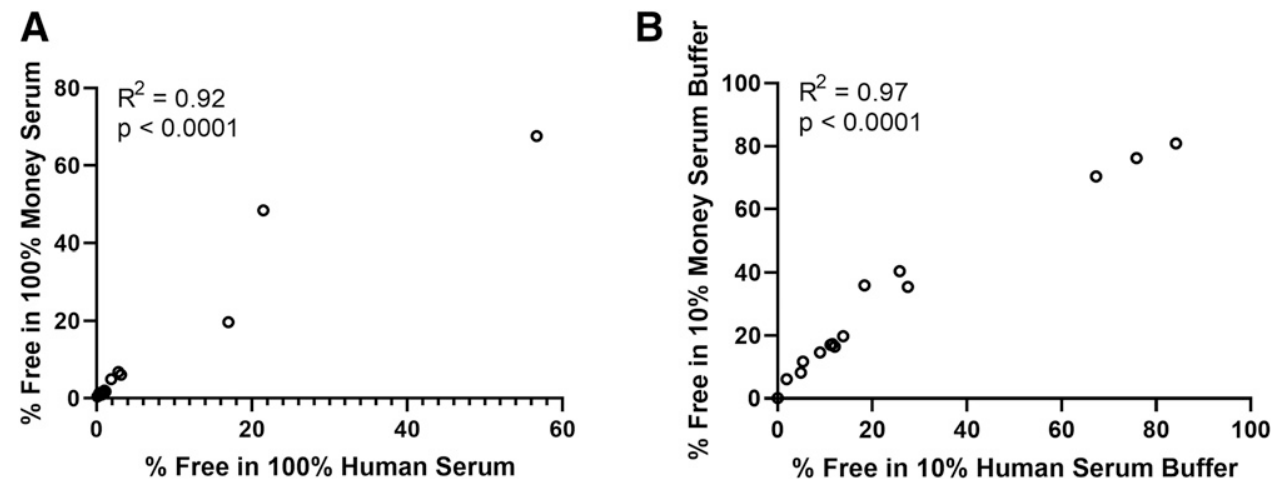

Fig. 1. The correlation of percentage free in $100 \%$ serum (A) and $10 \%$ serum buffer (B) in human and monkey. Sorafenib was excluded in the analysis in $100 \%$ serum (A) because it was too highly bound to be experimentally determined.

in vitro uptake assays were performed in the buffer with $10 \%$ respective human and monkey serum. The values of in vitro hepatic uptake clearance were then adjusted by the fraction of unbound in $10 \%$ serum

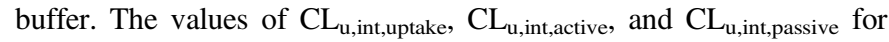
each donor in human and monkey hepatocytes are summarized in the Table 3. In general, the values of uptake clearances obtained from different lots were with 2-fold range, and the values of $\mathrm{CL}_{\mathrm{u} \text {,int,passive }}$ between human and monkey hepatocytes were comparable (two-tailed $P=0.4$ in Wilcoxon paired nonparametric test). One the other side, the

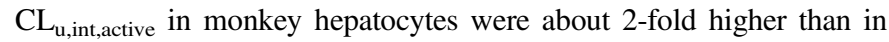

human hepatocytes (two-tailed $P=0.0001$ in Wilcoxon paired nonparametric test).

\section{Discussion}

As a general practice, in vitro metabolic stability is routinely examined using hepatic preparations, and hepatic uptake studies in suspended, plated, and sandwich-cultured hepatocytes are used to estimate hepatic transporter-mediated uptake clearance in early drug discovery. In vitro parameters obtained are then scaled to in vivo

TABLE 1

Summary of in vitro hepatic intrinsic clearance in buffer with and without serum

\begin{tabular}{|c|c|c|c|c|c|c|c|c|}
\hline & \multicolumn{3}{|c|}{ Serum free buffer } & \multicolumn{3}{|c|}{ Buffer with $10 \%$ serum } & \multicolumn{2}{|c|}{ Fold difference $^{\mathrm{b}}$} \\
\hline & $\mathrm{CL}_{\mathrm{u} \text {,int,uptake }}{ }^{\mathrm{a}}$ & $\mathrm{CL}_{\mathrm{u} \text {,int,passive }}{ }^{\mathrm{a}}$ & $\mathrm{CL}_{\mathrm{u}, \text { int,active }}{ }^{\mathrm{a}}$ & $\mathrm{CL}_{\mathrm{u}, \text { int,uptake }}{ }^{\mathrm{a}}$ & $\mathrm{CL}_{\mathrm{u}, \text { int,passive }}{ }^{\mathrm{a}}$ & $\mathrm{CL}_{\mathrm{u}, \text { int,active }}{ }^{\mathrm{a}}$ & $\mathrm{CL}_{\mathrm{u}, \text { int,passive }}$ & $\mathrm{CL}_{\mathrm{u} \text {,int,active }}$ \\
\hline \multicolumn{9}{|c|}{ Human hepatic uptake: lot XPM } \\
\hline Asunaprevir & $119.7(52.3)$ & $19.4(2.9)$ & 100.3 & $2448.1(242.4)$ & $154.8(40.7)$ & 2293.3 & 8.0 & 22.9 \\
\hline Atorvastatin & $47.9(2.0)$ & $5(1.9)$ & 42.9 & $138.7(12.3)$ & $7.3(2.5)$ & 131.4 & 1.5 & 3.1 \\
\hline Bosentan & $28.5(12.8)$ & $4.9(1.2)$ & 23.6 & $90.9(12.3)$ & $2.7(0.3)$ & 88.2 & 0.6 & 3.7 \\
\hline Cerivastatin & $57.4(16.1)$ & $5.3(0.1)$ & 52.1 & $223.3(79.3)$ & $10.1(2.9)$ & 213.3 & 1.9 & 4.1 \\
\hline Danoprevir & $43(8.5)$ & $6.2(2.0)$ & 36.8 & $167.6(79.3)$ & $17.1(5.4)$ & 150.5 & 2.8 & 4.1 \\
\hline Fluvastatin & $58.7(36.8)$ & $4.8(2.9)$ & 53.9 & $263.4(45.8)$ & $22.5(8.6)$ & 240.9 & 4.7 & 4.5 \\
\hline Grazoprevir & $94.6(28.6)$ & $12.4(2.9)$ & 82.2 & $774.3(191.1)$ & $34.6(10.1)$ & 739.7 & 2.8 & 9.0 \\
\hline Maraviroc & $4.4(0.08)$ & $0.6(0.3)$ & 3.8 & $6.6(1.8)$ & $0.8(0.1)$ & 5.8 & 1.3 & 1.5 \\
\hline Pitavastatin & $50.1(2.6)$ & $5(1.2)$ & 45.1 & $311.0(37.2)$ & $13.0(1.9)$ & 298.0 & 2.6 & 6.6 \\
\hline Pravastatin & $2.3(0.7)$ & $0.6(0.2)$ & 1.7 & $3.4(1.1)$ & $0.6(0.04)$ & 2.9 & 1.0 & 1.7 \\
\hline Repaglinide & $62.3(18.2)$ & $14.3(3.9)$ & 48 & 257.9 (111.6) & $10.7(1.7)$ & 247.1 & 0.8 & 5.1 \\
\hline Rosuvastatin & $13.5(2.2)$ & $1.4(0.7)$ & 12.1 & $20.1(1.6)$ & $1.3(0.1)$ & 18.7 & 1.0 & 1.5 \\
\hline Sorafenib & $215.9(67.1)$ & $44.3(20.6)$ & 171.6 & $167,666.7(20,000.0)$ & $9000.0(2000.0)$ & $158,666.7$ & 203.2 & 924.6 \\
\hline Telmisartan & $156.2(15.7)$ & $26.8(5.6)$ & 129.4 & $1043.8(300.5)$ & $53.7(48.3)$ & 990.2 & 2.0 & 7.7 \\
\hline Valsartan & $7.5(1.2)$ & $2.3(0.9)$ & 5.2 & $105.8(5.3)$ & $26.5(5.3)$ & 79.4 & 11.5 & 15.3 \\
\hline \multicolumn{9}{|c|}{ Monkey hepatic uptake: lot UHK } \\
\hline Asunaprevir & $205.7(46.9)$ & $20.7(4.2)$ & 185 & $2224.5(169.9)$ & $76.5(42.5)$ & 2148.1 & 3.69 & 11.61 \\
\hline Atorvastatin & $119.7(10.7)$ & $5.7(4.2)$ & 114 & $414.3(68.5)$ & $7.0(5.9)$ & 407.3 & 1.24 & 3.57 \\
\hline Bosentan & $56(6.4)$ & $3(0.8)$ & 53 & $380.2(46.2)$ & $5.0(6.4)$ & 375.2 & 1.67 & 7.08 \\
\hline Cerivastatin & $77.3(12.9)$ & $4.3(3.2)$ & 73 & $415.2(32.8)$ & $9.6(7.1)$ & 405.6 & 2.23 & 5.56 \\
\hline Danoprevir & $99.7(22.3)$ & $5.4(0.9)$ & 94.3 & $355.5(116.0)$ & $6.2(5.2)$ & 349.3 & 1.15 & 3.70 \\
\hline Fluvastatin & $88(15.5)$ & $5.4(1.9)$ & 82.6 & $265.7(24.8)$ & $6.4(1.7)$ & 259.4 & 1.18 & 3.14 \\
\hline Grazoprevir & $156.4(33.1)$ & $19.8(2.8)$ & 136.6 & $1145.1(488)$ & $36.3(4.8)$ & 1108.8 & 1.83 & 8.12 \\
\hline Maraviroc & $18(2.0)$ & $0.5(0.4)$ & 17.5 & $22.2(2.9)$ & $0.4(0.3)$ & 21.8 & 0.79 & 1.25 \\
\hline Pitavastatin & $125.4(17.5)$ & $3.2(2.3)$ & 122.2 & $620.1(103.9)$ & $8.5(1.7)$ & 611.6 & 2.66 & 5.00 \\
\hline Pravastatin & $7.8(0.6)$ & $0.5(0.2)$ & 7.3 & $8.2(0.7)$ & $0.7(0.1)$ & 7.4 & 1.48 & 1.02 \\
\hline Repaglinide & $251.8(37.5)$ & $14.9(2.3)$ & 236.9 & $552.8(230.6)$ & $14.0(29.1)$ & 538.8 & 0.94 & 2.27 \\
\hline Rosuvastatin & $33.8(3.7)$ & $1.2(0.6)$ & 32.6 & $51.6(9.8)$ & $1.7(0.3)$ & 49.9 & 1.42 & 1.53 \\
\hline Sorafenib & $241(66.4)$ & $62.2(47.9)$ & 178.8 & $175,428.6(37,642.9)$ & $18,357.1(8642.9)$ & $157,071.4$ & 295.13 & 878.48 \\
\hline Telmisartan & $313.8(69.8)$ & $44.1(15.2)$ & 269.7 & $2416.3(167.4)$ & $138.0(24.1)$ & 2278.3 & 3.13 & 8.45 \\
\hline Valsartan & $21.6(1.9)$ & $1.9(0.3)$ & 19.7 & $252.0(8.1)$ & $8.1(2.1)$ & 243.9 & 4.28 & 12.38 \\
\hline
\end{tabular}

${ }^{a}$ The in vitro uptake clearance was assessed in single donor of human (lot XPM) and monkey (lot UHK) hepatocytes. The initial uptake rates were estimated from the slopes of linear uptake phase

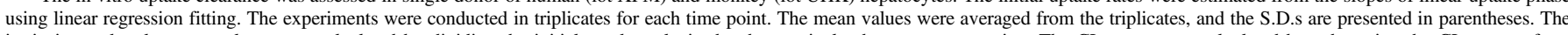

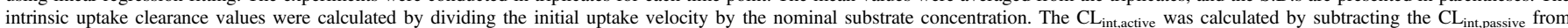

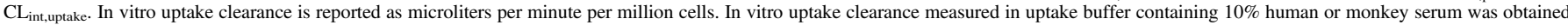
by normalizing the free fraction of protein binding in $10 \%$ serum buffer.

${ }^{b}$ Fold difference $=\mathrm{CL}_{\mathrm{u}, \text { int }}$ in $10 \%$ serum buffer/ $\mathrm{CL}_{\mathrm{u} \text {,int }}$ in serum free buffer. 
A

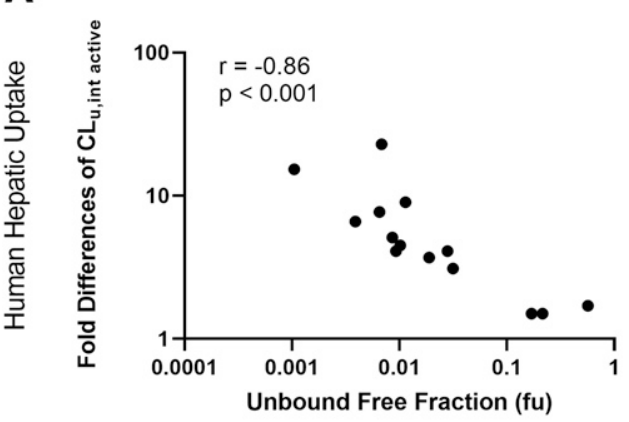

C

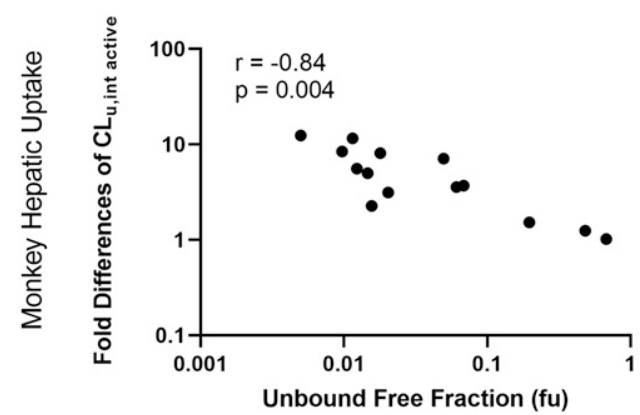

B

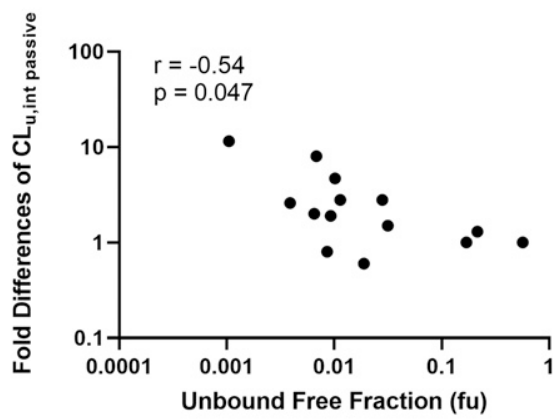

D

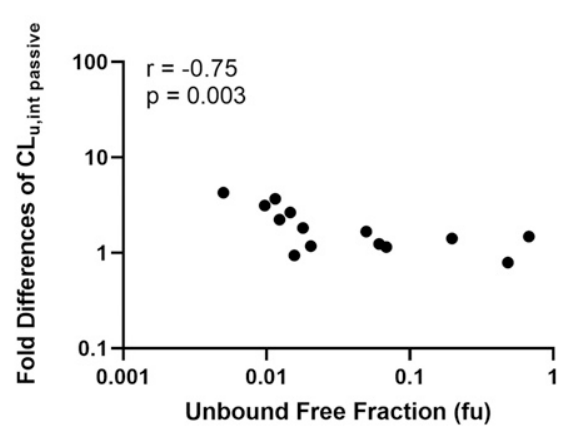

Fig. 2. The correlation of serum protein binding values vs. the fold differences of $\mathrm{CL}_{\mathrm{u} \text {,int,active }}$ or $\mathrm{CL}_{\mathrm{u} \text {,int,passive values obtained }}$ by normalizing the unbound fraction in the buffer containing $10 \%$ serum protein and obtained directly from the uptake with the protein free buffer for OATP substrates. The fold difference in human $\mathrm{CL}_{\mathrm{u} \text {,int,active }}(\mathrm{A})$ and $\mathrm{CL}_{\mathrm{u} \text {,int,passive }}(\mathrm{B})$. The fold difference in monkey $\mathrm{CL}_{\mathrm{u} \text {,int,active }}(\mathrm{C})$ and $\mathrm{CL}_{\mathrm{u} \text {,int,passive }}(\mathrm{D})$. clearances by multiplying the hepatocellularlarity and liver weight $(\mathrm{Li}$ et al., 2009; Bi et al., 2012). Although this physiologically based IVIVE appears to be the best approach, systematic underprediction is a well known issue (Yamagata et al., 2017; Bowman and Benet, 2019). To bridge the gap of transporter-mediated clearance IVIVE, empirically derived SFs were widely used to parametrize the transporter-associated clearance such as $\mathrm{CL}_{\mathrm{u} \text {,int,active }}, \mathrm{CL}_{\mathrm{u} \text {,int,passive, and unbound intrinsic }}$ biliary clearance $\left(\mathrm{CL}_{\mathrm{u}, \text { int,bile }}\right)$. In addition, confidence in the prediction is low for the compounds that are less permeable and subject to transporter substrates with high protein binding (Jones et al., 2012, 2015; Yamagata et al., 2017; De Bruyn et al., 2018). Recently, Kim et al. showed that the $\mathrm{CL}_{\mathrm{u} \text {,int,active }}$ increases in the presence of human serum albumin for 11 highly protein bound drugs (Kim et al., 2019). As a result, an improved IVIVE for 11 OATP substrates was achieved using uptake parameters obtained from the incubation in the presence of human serum protein (Kim et al., 2019). Moreover, Bowman et al. also showed similar results by doing uptake studies in the presence of $100 \%$ plasma for high protein binding substrates such as atorvastatin and pitavastatin in fresh isolated rat hepatocytes (Bowman et al., 2019). Collectively, a theory of "proteinfacilitated" or "transporter-induced protein binding shift" uptake was proposed for the improved IVIVE (Baik and Huang, 2015; Zhang et al., 2015; Miyauchi et al., 2018; Bowman et al., 2019). In the present investigation, we measured the in vitro $\mathrm{CL}_{\text {int,uptake }}$ in suspension hepatocytes in the buffer with or without $10 \%$ human or cynomolgus

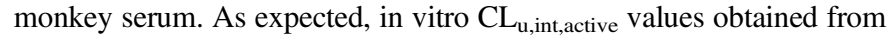
the incubation in the buffer containing $10 \%$ serum were greatly

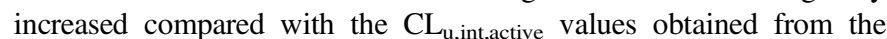
incubation in protein free buffer (Table 1). The fold differences highly correlated with the protein binding (Fig. 2), with particularly larger differences being observed for the drugs that were highly protein bound, such as sorafenib (925-fold), asunaprevir (23-fold), and valsartan (15fold) in human hepatocytes. Similar results were observed in monkey

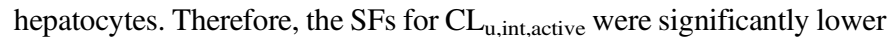
for each compound, especially for highly protein bound drugs, when using scaled $\mathrm{CL}_{\mathrm{u} \text {,int,active }}$ from the incubation in the buffer containing $10 \%$ serum protein (Table 2). As expected, less fold shift was observed for lower protein binding compounds such as rosuvastatin and pravastatin. Interestingly, the larger empirical SFs were needed for pravastatin IVIVE in both human and in monkey, which is consistent with the recent report by De Bruyn et al. (2018). These data suggested that uptake clearance of pravastatin was significantly underestimated in vitro, even in the incubation with serum protein. Pravastatin has been reported to be a substrate for many other uptake and efflux transporters (Table 4), and the protein binding is low (57\% free in human serum)
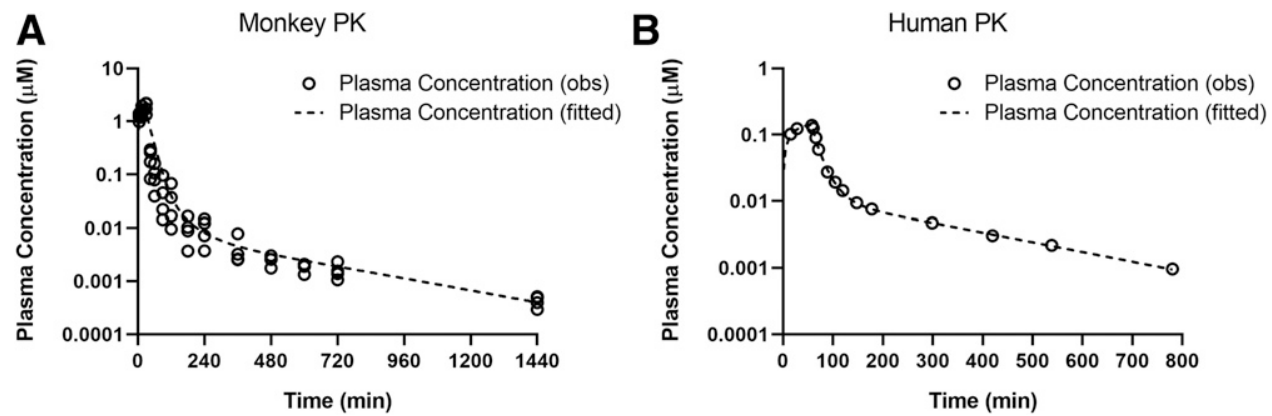

Fig. 3. Curve fitting of pitavastatin intravenous plasma PK in monkey (A) and human (B) using a PBPK model. The open circle represents in vivo observed data (obs), and the dotted line represents the simulation PK curve. The in vivo monkey plasma data were from in-house PK study, and human plasma data were digitalized (GetData Graph Digitizer version 2.26.0) from previously published New Drug Application (NDA022363). 
TABLE 2

The in vitro to in vivo scaling factors estimated for literature compounds

\begin{tabular}{|c|c|c|c|c|c|c|c|c|c|c|}
\hline \multirow[b]{2}{*}{ Compound } & \multicolumn{2}{|c|}{ In vivo fitted parameters } & \multicolumn{4}{|c|}{ Serum free buffer in vitro scaled-up parameters ${ }^{\mathrm{d}}$} & \multicolumn{4}{|c|}{$10 \%$ human or monkey serum buffer In vitro scaled-up parameters } \\
\hline & $\mathrm{CL}_{\mathrm{u}, \text { int,passive }}$ & $\mathrm{CL}_{\mathrm{u}, \text { int, active }}$ & $\mathrm{CL}_{\mathrm{u} \text {,int,passive }}$ & $\mathrm{CL}_{\mathrm{u}, \text { int,active }}$ & $\begin{array}{c}\mathrm{SF} 1^{\mathrm{e}} \\
\mathrm{CL}_{\mathrm{u}, \text { int,passive }}\end{array}$ & $\begin{array}{c}\mathrm{SF} 1^{\mathrm{e}} \\
\mathrm{CL}_{\mathrm{u}, \text { int,active }}\end{array}$ & $\mathrm{CL}_{\mathrm{u}, \text { int,passive }}$ & $\mathrm{CL}_{\mathrm{u}, \text { int, active }}$ & $\begin{array}{c}\mathrm{SF} 2^{\mathrm{e}} \\
\mathrm{CL}_{\mathrm{u}, \text { int,passive }}\end{array}$ & $\mathrm{SF} 2^{\mathrm{e}} \mathrm{CL}_{\mathrm{u}, \text { int,active }}$ \\
\hline \multicolumn{11}{|l|}{ Human } \\
\hline Bosentan $^{\mathrm{a}}$ & 59 & 8489 & 65.6 & 315.9 & 0.9 & 26.9 & 36.1 & 1180.8 & 1.6 & 7.2 \\
\hline Cerivastatin $^{\mathrm{a}}$ & 153 & 12,827 & 71.0 & 697.5 & 2.2 & 18.4 & 135.2 & 2855.6 & 1.1 & 4.5 \\
\hline Fluvastatin $^{\mathrm{a}}$ & 147 & 76,513 & 64.3 & 721.6 & 2.3 & 106.0 & 301.2 & 3225.0 & 0.5 & 23.7 \\
\hline Pitavastatin $^{\mathrm{c}}$ & 52.6 & $16,071.3$ & 66.9 & 603.8 & 0.8 & 26.6 & 174.0 & 3989.5 & 0.3 & 4.0 \\
\hline Pravastatin $^{\mathrm{a}}$ & 4.2 & 406 & 8.0 & 22.8 & 0.5 & 17.8 & 8.0 & 38.8 & 0.5 & 10.5 \\
\hline Repaglinide $^{\mathrm{a}}$ & 1477 & 13,941 & 191.4 & 642.6 & 7.7 & 21.7 & 143.2 & 3308.1 & 10.3 & 4.2 \\
\hline Rosuvastatin $^{\mathrm{a}}$ & 1.7 & 1190 & 18.7 & 162.0 & 0.1 & 7.3 & 17.4 & 250.3 & 0.1 & 4.8 \\
\hline Valsartan $^{\mathrm{a}}$ & 23 & 2463 & 30.8 & 69.6 & 0.7 & 35.4 & 354.8 & 1063.0 & 0.1 & 2.3 \\
\hline Median & & & & & 0.8 & 24.2 & & & 0.5 & 4.6 \\
\hline \multicolumn{11}{|l|}{ Monkey } \\
\hline Bosentan $^{\mathrm{b}}$ & 2.1 & 595.8 & 0.4 & 7.8 & 4.7 & 76.8 & 0.7 & 54.9 & 2.8 & 10.8 \\
\hline Pitavastatin $^{\mathrm{c}}$ & 0.2 & 405.7 & 0.5 & 17.9 & 0.4 & 22.7 & 1.2 & 89.5 & 0.2 & 4.5 \\
\hline Rosuvastatin $^{\mathrm{b}}$ & 0.2 & 52.2 & 0.2 & 4.8 & 0.9 & 10.9 & 0.2 & 7.3 & 0.6 & 7.1 \\
\hline Median & & & & & 0.9 & 22.7 & & & 0.6 & 7.1 \\
\hline
\end{tabular}

${ }^{a}$ In vivo fitted intrinsic clearance in human (except for pitavastatin) was reported previously (Jones et al., 2012).

${ }^{b}$ In vivo fitted intrinsic clearance (bosentan and rosuvastatin) in monkey were from Morse et al. (2017).

${ }^{c}$ In vivo fitted intrinsic clearance of Pitavastatin in human and monkey was modeled in house.

${ }^{d}$ In vitro scaled intrinsic clearance was calculated by in vitro uptake clearance $\times$ hepatocellularity $\times$ liver weigh per body weight. Human is assumed to have $70 \mathrm{~kg}$ body weight.

${ }^{e} \mathrm{SF} 1=$ in vivo fitted value/in vitro scaled value in serum free buffer; SF2 = in vivo fitted value/in vitro scaled value in $10 \%$ serum buffer.

(Supplemental Table 4). In addition, renal elimination also significantly contributes to overall systemic clearance (pravastatin drug label). In addition, previous publication suggested addition of protein had effect on both $\mathrm{V}_{\max }$ and $\mathrm{K}_{\mathrm{m}}$ of transport kinetics (Bowman et al., 2019, 2020; Kim et al., 2019). In the present study, only a single concentration was used in the uptake assay. Thus, further studies on the contribution of each transporter, the preservation of transporter function in cryopreserved hepatocytes, the changes of $\mathrm{V}_{\max }$ and $\mathrm{K}_{\mathrm{m}}$ in the presence of serum protein, and IVIVE involved various elimination pathways are warranted. Nevertheless, the empirical SFs in the present investigation appeared to be comparable with the literature SFs using uptake values obtained from the incubation with $5 \%$ human serum albumin (Kim et al., 2019).

Moreover, recent published studies (Bowman et al., 2019, 2020) and as well as our present investigation showed that passive diffusion also increased with addition of protein in the uptake experiments as a result of

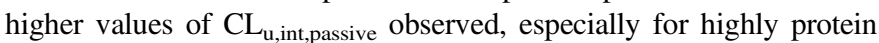
bound compounds (Fig. 2; Table 1). The data suggested that protein affected both active uptake and passive diffusion. One possible mechanism is changing the interaction between the binding to the serum protein and nonspecific binding to the cells membrane when adding protein to uptake buffer. For example, the serum protein (with compound highly bound) may bind to cell membrane during the incubation, and the binding of serum protein on the cell membrane may be not fully washed with buffer or separated by the oil layer. When we lysed cells, the cell membrane fraction was included in the analysis. Such contamination may confound the results. Another possible reason is that the solutes in plasma/serum may change the osmotic pressure of cell membrane, which may be different in protein free buffer. As in previous reports, even in an isotonic environment, animal cells face a problem in maintaining cell volume (Lodish et al., 2000). The solutes and other molecules in the plasma/serum may affect the function of ATP- $\mathrm{Na}^{+} / \mathrm{K}^{+}$pump and ion movements and sequentially change the cell volume and surface area. As the intrinsic clearance of passive diffusion can be defined as the permeability-surface area, the change of cell volume and surface area may affect passive diffusion. Collectively, the mechanisms of protein affecting passive diffusion remain unknown. Further investigation is needed in this field.
Many studies showed that a "middle-out" approach can reasonably capture clinical PK profiles and predict clinical DDIs when using PBPK models (Varma et al., 2012; Barton et al., 2013; Duan et al., 2017). Unfortunately, human PK data are unlikely to be available during drug discovery and early development phase, which limits the application of the "middle-out" modeling. As such, to incorporate transporter-mediated clearance for human PK prediction during compound selection and engage PBPK modeling along lead optimization, one of critical options is to derive SFs from preclinical species and apply the SFs for prospective human PK prediction. However, concerns remain when translating preclinical animal data to human due to poor protein homology for drug transporters. Being a species with a high degree of homology to human OATP isoforms (Shen et al., 2013; Kimoto et al., 2017; De Bruyn et al., 2018), cynomolgus monkey is a promising preclinical species that can be used in transporter characterization to bridge the gaps of human IVIVE. As such, we further characterized hepatic uptake in human and monkey hepatocytes under the condition in the buffer containing 10\% serum. Three hepatocyte lots were included in the uptake studies for each species to evaluate variation among difference lots or donors. As shown in Table 3, among 15 known OATP and other transporter substrates (Table 4), the uptake values in different lots were generally within 2-fold. Although the binding to hepatocytes cannot be ignored in the incubation, the binding to the hepatocytes should be similar in both human and monkey. After the correction of serum binding, the values of in vitro $\mathrm{CL}_{\mathrm{u}}$,int,passive were generally comparable between human and monkey. On the other hand, in vitro $\mathrm{CL}_{\mathrm{u} \text {,int,active }}$ in monkey was signifyingly higher than in human ( $>2$-fold) and appeared to be compound dependent (Table 3). It is worth

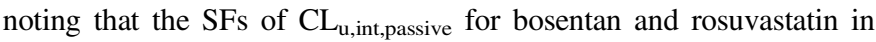
monkey were higher than in human, although the SFs of $\mathrm{CL}_{\mathrm{u} \text {,int,active }}$ were comparable (Table 2). As the data of protein binding in $10 \%$ serum buffer (Supplemental Table 4) and the values of in vitro $\mathrm{CL}_{\mathrm{u} \text {,int,passive }}$ were comparable in human and monkey for both bosentan and rosuvastatin, therefore, the large difference of $\mathrm{SFs}$ in $\mathrm{CL}_{\mathrm{u} \text {,int,passive }}$ between human and monkey was less likely due to in vitro experiments. For bosentan and rosuvastatin, the PBPK modeling of human and monkey were performed by two different groups. In addition, the curve fitting in human PBPK solely relied on plasma PK data (Jones et al., 


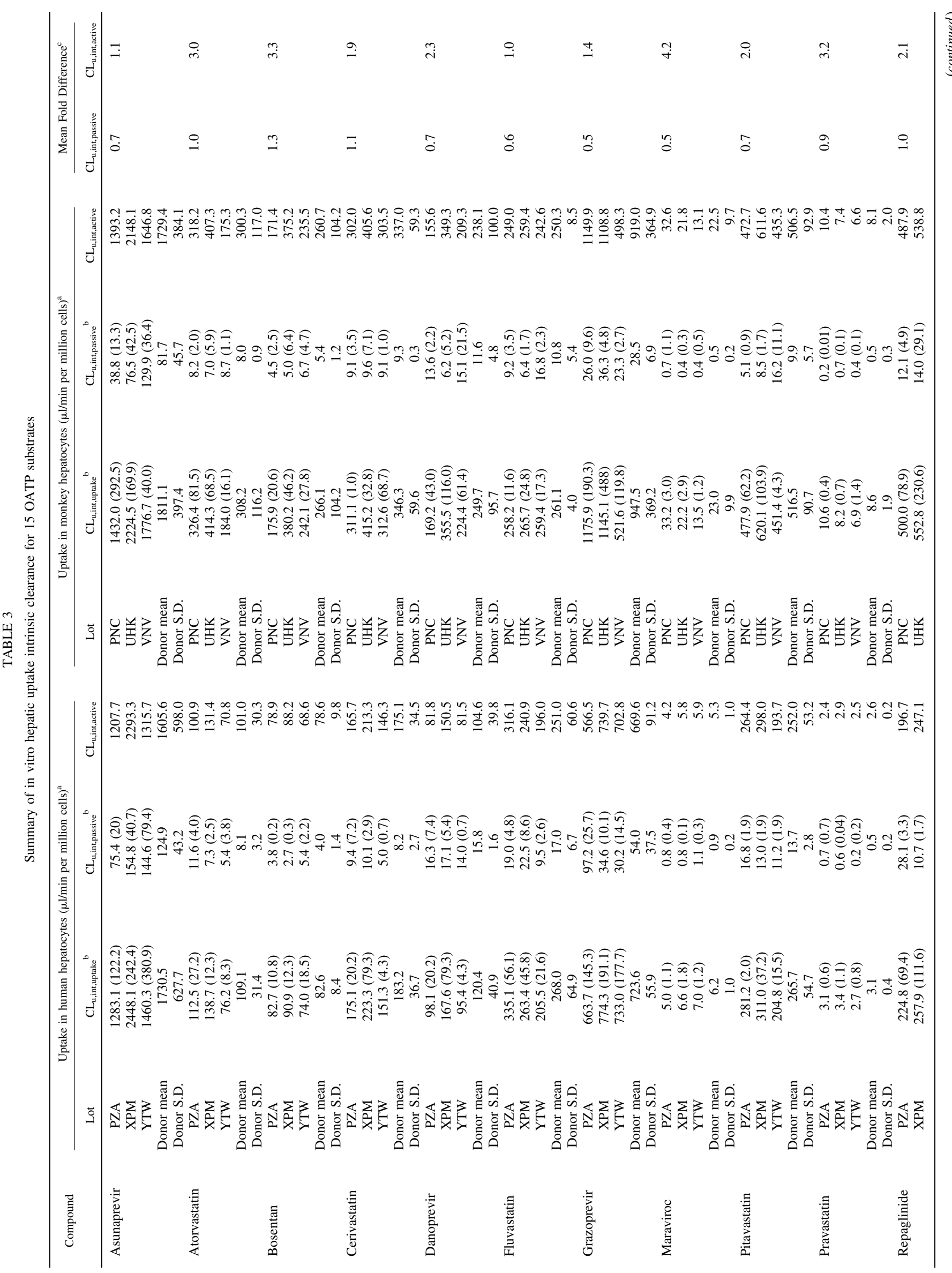


Liang et al.

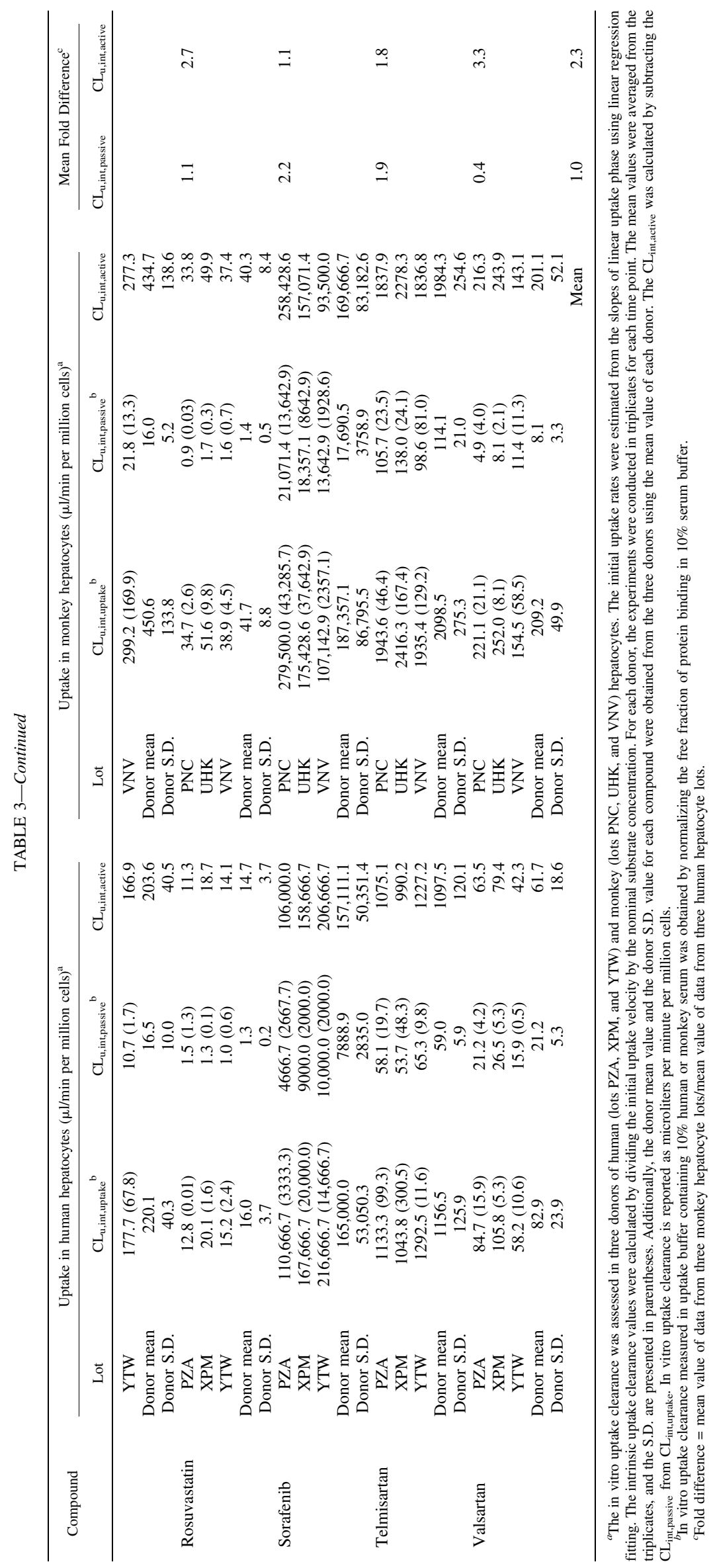


TABLE 4

Summary of transporters involved in transporting selected compounds in human

The uptake and efflux transporters of each selected compounds are summarized from Drug Interaction Solution Database, University of Washington (https://didb.druginteractionsolutions.org).

\begin{tabular}{|c|c|c|c|}
\hline Compound & OATPs & OATs & Other transporters \\
\hline Rosuvastatin & $1 \mathrm{~A} 2,1 \mathrm{~B} 1,1 \mathrm{~B} 3,2 \mathrm{~B} 1$ & OAT3 & NTCP, BCRP, MRP1-5, P-gp \\
\hline Cerivastatin & $1 \mathrm{~B} 1,1 \mathrm{~B} 3,2 \mathrm{~B} 1$ & & P-gp, BCRP, MRPs \\
\hline Fluvastatin & $1 \mathrm{~B} 1,1 \mathrm{~B} 3,2 \mathrm{~B} 1$ & & NTCP, BCRP, MRP2, P-gp \\
\hline Pitavastatin & $1 \mathrm{~A} 2,1 \mathrm{~B} 1,1 \mathrm{~B} 3,2 \mathrm{~B} 1$ & & NTCP, BCRP, MRP3, MRP4, P-gp \\
\hline Atorvastatin & $1 \mathrm{~A} 2,1 \mathrm{~B} 1,1 \mathrm{~B} 3,2 \mathrm{~B} 1$ & & NTCP, BCRP, MRP1, MRP2, MRP4, P-gp \\
\hline Sorafenib & $1 \mathrm{~B} 1,1 \mathrm{~B} 3$ & & OCT1, MRP2, P-gp \\
\hline Pravastatin & $1 \mathrm{~A} 2,1 \mathrm{~B} 1,1 \mathrm{~B} 3,2 \mathrm{~B} 1$ & OAT3, OAT4, OAT7 & NTCP, BCRP, MRP1, MRP2, MRP4, MRP5, BSEP, P-gp \\
\hline Danoprevir & $1 \mathrm{~B} 1,1 \mathrm{~B} 3$ & & MRP2, P-gp \\
\hline Maraviroc & $1 \mathrm{~B} 1$ & & P-gp \\
\hline Bosentan & 1B1, 1B3, 2B1 & & MRP2, P-gp \\
\hline Repaglinide & $1 \mathrm{~B} 1,1 \mathrm{~B} 3$ & & P-gp \\
\hline Grazoprevir & $1 \mathrm{~B} 1,1 \mathrm{~B} 3$ & & BCRP, P-gp \\
\hline Telmisartan & $1 \mathrm{~B} 3,2 \mathrm{~B} 1$ & & \\
\hline Asunaprevir & $1 \mathrm{~B} 1,2 \mathrm{~B} 1$ & & P-gp \\
\hline Valsartan & $1 \mathrm{~B} 1,1 \mathrm{~B} 3$ & OAT1, OAT3 & MRP2, P-gp \\
\hline
\end{tabular}

2012), whereas both liver and plasma data were used in curve fitting in monkey model (Morse et al., 2017). Different models and fitting process may contribute to the different $\mathrm{SFs}$ of $\mathrm{CL}_{\mathrm{u} \text {,int,passive }}$ obtained in human and monkey for bosentan and rosuvastatin. In the case of pitavastatin, both human and monkey PBPK models were developed in house for plasma PK curve fitting; the $S F$ s of $\mathrm{CL}_{\mathrm{u} \text {,int,passive }}$ and $\mathrm{CL}_{\mathrm{u} \text {,int,active were }}$ comparable between human and monkey (Table 2). Although the serum protein binding data were correlated well among these 15 compounds between human and monkey (Fig. 1), another study observed poor correlation of protein binding between preclinical species and human (Lombardo et al., 2013). In this regard, when interpreting protein facilitated uptake clearance and translating from preclinical animal to human, it is recommended to consider the species difference in protein binding as well as the difference in transport kinetics. Nevertheless, since overall difference of hepatic uptake obtained from the incubation in the buffer containing serum proteins incorporates multiple speciesspecific variables to compensate the complexities affecting the hepatic uptake, such as difference of transporter expression, the relative contribution of each transporter, substrate affinity of each transporter, and protein binding, SFs derived from the IVIVE in monkey can be reliably used in PBPK models for prospective human PK prediction.

In summary, the IVIVE of transporter-mediated clearance was significantly improved when using hepatic uptake parameters obtained from the incubation with serum protein in the uptake experiments. The species differences were found in hepatic uptakes between money and human hepatocytes for 15 known OATP substrates, and the difference appeared to be substrate dependent. As compound advancing during drug discovery and early development, cynomolgus monkeys can serve as a good preclinical animal model to probe the SFs of transportermediated uptake parameters for prospective human PK prediction.

\section{Acknowledgments}

We thank Drs. Bernard Murray and Yang Song for helpful scientific discussions.

\section{Authorship Contributions}

Participated in research design: Liang, Smith, Lai.

Conducted experiments: Liang, Park, DeForest, Hao, Zhao, Niu, Wang.

Performed data analysis: Liang, Park, Hao, Zhao, Lai.

Wrote or contributed to the writing of the manuscript: Liang, Park, Lai.

\section{References}

Baik J and Huang Y (2015) Transporter-induced protein binding shift (TIPBS) hypothesis and modeling. Poster in 20th North American ISSX Meeting; 2015 Oct 18-22; Orlando, FL.
Barton HA, Lai Y, Goosen TC, Jones HM, El-Kattan AF, Gosset JR, Lin J, and Varma MV (2013) Model-based approaches to predict drug-drug interactions associated with hepatic uptake transporters: preclinical, clinical and beyond. Expert Opin Drug Metab Toxicol 9:459-472.

Benet LZ, Bowman CM, Liu S, and Sodhi JK (2018) The extended clearance concept following oral and intravenous dosing: theory and critical analyses. Pharm Res 35:242.

Bi YA, Kimoto E, Sevidal S, Jones HM, Barton HA, Kempshall S, Whalen KM, Zhang H, Ji C, Fenner KS, et al. (2012) In vitro evaluation of hepatic transporter-mediated clinical drug-drug interactions: hepatocyte model optimization and retrospective investigation. Drug Metab Dispos 40:1085-1092.

Bowman CM and Benet LZ (2019) In vitro-in vivo extrapolation and hepatic clearance-dependent underprediction. J Pharm Sci 108:2500-2504.

Bowman CM, Chen E, Chen L, Chen YC, Liang X, Wright M, Chen Y, and Mao J (2020) Changes in organic anion transporting polypeptide uptake in HEK293 overexpressing cells in the presence and absence of human plasma. Drug Metab Dispos 48:18-24.

Bowman CM, Okochi H, and Benet LZ (2019) The presence of a transporter-induced protein binding shift: a new explanation for protein-facilitated uptake and improvement for in vitro-in vivo extrapolation. Drug Metab Dispos 47:358-363.

Chiba M, Ishii Y, and Sugiyama Y (2009) Prediction of hepatic clearance in human from in vitro data for successful drug development. AAPS J 11:262-276.

De Bruyn T, Ufuk A, Cantrill C, Kosa RE, Bi YA, Niosi M, Modi S, Rodrigues AD, Tremaine LM, Varma MVS, et al. (2018) Predicting human clearance of organic anion transporting polypeptide substrates using cynomolgus monkey: in vitro-in vivo scaling of hepatic uptake clearance. Drug Metab Dispos 46:989-1000.

Duan P, Zhao P, and Zhang L (2017) Physiologically based pharmacokinetic (PBPK) modeling of pitavastatin and atorvastatin to predict drug-drug interactions (DDIs). Eur J Drug Metab Pharmacokinet 42:689-705.

El-Kattan AF, Varma MV, Steyn SJ, Scott DO, Maurer TS, and Bergman A (2016) Projecting ADME behavior and drug-drug interactions in early discovery and development: application of the extended clearance classification system. Pharm Res 33:3021-3030.

Ito K and Houston JB (2005) Prediction of human drug clearance from in vitro and preclinical data using physiologically based and empirical approaches. Pharm Res 22:103-112.

Jones HM, Barton HA, Lai Y, Bi YA, Kimoto E, Kempshall S, Tate SC, El-Kattan A, Houston JB, Galetin A, et al. (2012) Mechanistic pharmacokinetic modeling for the prediction of transportermediated disposition in humans from sandwich culture human hepatocyte data. Drug Metab Dispos 40:1007-1017

Jones HM, Chen Y, Gibson C, Heimbach T, Parrott N, Peters SA, Snoeys J, Upreti VV, Zheng M, and Hall SD (2015) Physiologically based pharmacokinetic modeling in drug discovery and development: a pharmaceutical industry perspective. Clin Pharmacol Ther 97:247-262.

Kim SJ, Lee KR, Miyauchi S, and Sugiyama Y (2019) Extrapolation of in vivo hepatic clearance from in vitro uptake clearance by suspended human hepatocytes for anionic drugs with high binding to human albumin: improvement of in vitro-to-in vivo extrapolation by considering the "albumin-mediated" hepatic uptake mechanism on the basis of the "facilitated-dissociation model". Drug Metab Dispos 47:94-103.

Kimoto E, Bi YA, Kosa RE, Tremaine LM, and Varma MVS (2017) Hepatobiliary clearance prediction: species scaling from monkey, dog, and rat, and in vitro-in vivo extrapolation of sandwich-cultured human hepatocytes using 17 drugs. J Pharm Sci 106:2795-2804.

Kimoto E, Chupka J, Xiao Y, Bi YA, and Duignan DB (2011) Characterization of digoxin uptake in sandwich-cultured human hepatocytes. Drug Metab Dispos 39:47-53.

Kunze A, Poller B, Huwyler J, and Camenisch G (2015) Application of the extended clearance concept classification system (ECCCS) to predict the victim drug-drug interaction potential of statins. Drug Metab Pers Ther 30:175-188.

Lai Y, Sampson KE, and Stevens JC (2010) Evaluation of drug transporter interactions in drug discovery and development. Comb Chem High Throughput Screen 13:112-134.

Lai Y, Varma M, Feng B, Stephens JC, Kimoto E, El-Kattan A, Ichikawa K, Kikkawa H, Ono C, Suzuki A, et al. (2012) Impact of drug transporter pharmacogenomics on pharmacokinetic and pharmacodynamic variability - considerations for drug development. Expert Opin Drug Metab Toxicol 8:723-743.

Li N, Bi YA, Duignan DB, and Lai Y (2009) Quantitative expression profile of hepatobiliary transporters in sandwich cultured rat and human hepatocytes. Mol Pharm 6:1180-1189.

Li N, Singh P, Mandrell KM, and Lai Y (2010) Improved extrapolation of hepatobiliary clearance from in vitro sandwich cultured rat hepatocytes through absolute quantification of hepatobiliary transporters. Mol Pharm 7:630-641. 
Lodish H, Berk A, Zipursky S, Matsudaira P, Baltimore D, and Darnell J (2000) Osmosis, water channels, and the regulation of cell volume, in Molecular Cell Biology, W. H. Freeman, New York.

Lombardo F, Waters NJ, Argikar UA, Dennehy MK, Zhan J, Gunduz M, Harriman SP, Berellini G, Liric Rajlic I, and Obach RS (2013) Comprehensive assessment of human pharmacokinetic prediction based on in vivo animal pharmacokinetic data, part 2: clearance. J Clin Pharmacol 53:178-191.

Miyauchi S, Masuda M, Kim SJ, Tanaka Y, Lee KR, Iwakado S, Nemoto M, Sasaki S, Shimono K, Tanaka Y, et al. (2018) The phenomenon of albumin-mediated hepatic uptake of organic anion transport polypeptide substrates: prediction of the in vivo uptake clearance from the in vitro uptake by isolated hepatocytes using a facilitated-dissociation model. Drug Metab Dispos 46:259-267.

Morse BL, Cai H, MacGuire JG, Fox M, Zhang L, Zhang Y, Gu X, Shen H, Dierks EA, Su H, et al. (2015) Rosuvastatin liver partitioning in cynomolgus monkeys: measurement in vivo and prediction using in vitro monkey hepatocyte uptake. Drug Metab Dispos 43:1788-1794.

Morse BL, MacGuire JG, Marino AM, Zhao Y, Fox M, Zhang Y, Shen H, Griffith Humphreys W, Marathe P, and Lai Y (2017) Physiologically based pharmacokinetic modeling of transportermediated hepatic clearance and liver partitioning of OATP and OCT substrates in cynomolgus monkeys. AAPS J 19:1878-1889.

Obach RS, Baxter JG, Liston TE, Silber BM, Jones BC, MacIntyre F, Rance DJ, and Wastall P (1997) The prediction of human pharmacokinetic parameters from preclinical and in vitro metabolism data. $J$ Pharmacol Exp Ther 283:46-58.

Patilea-Vrana G and Unadkat JD (2016) Transport vs. metabolism: what determines the pharmacokinetics and pharmacodynamics of drugs? Insights from the extended clearance model. Clin Pharmacol Ther 100:413-418.

Shen H, Yang Z, Mintier G, Han YH, Chen C, Balimane P, Jemal M, Zhao W, Zhang R, Kallipatti $\mathrm{S}$, et al. (2013) Cynomolgus monkey as a potential model to assess drug interactions involving hepatic organic anion transporting polypeptides: in vitro, in vivo, and in vitro-to-in vivo extrapolation. J Pharmacol Exp Ther 344:673-685.
Sirianni GL and Pang KS (1997) Organ clearance concepts: new perspectives on old principles. $J$ Pharmacokinet Biopharm 25:449-470.

Varma MV, Lai Y, Feng B, Litchfield J, Goosen TC, and Bergman A (2012) Physiologically based modeling of pravastatin transporter-mediated hepatobiliary disposition and drug-drug interactions. Pharm Res 29:2860-2873.

Watanabe T, Kusuhara H, Maeda K, Shitara Y, and Sugiyama Y (2009) Physiologically based pharmacokinetic modeling to predict transporter-mediated clearance and distribution of pravastatin in humans. J Pharmacol Exp Ther 328:652-662.

Yamagata T, Zanelli U, Gallemann D, Perrin D, Dolgos H, and Petersson C (2017) Comparison of methods for the prediction of human clearance from hepatocyte intrinsic clearance for a set of reference compounds and an external evaluation set. Xenobiotica 47:741-751.

Yee SW, Brackman DJ, Ennis EA, Sugiyama Y, Kamdem LK, Blanchard R, Galetin A, Zhang L, and Giacomini KM (2018) Influence of transporter polymorphisms on drug disposition and response: a perspective from the International Transporter Consortium. Clin Pharmacol Ther 104:803-817.

Zhang X, Baik J, Jahic M, Jiang W, and Huang Y (2015) In vitro evidence of OATP1B1 induced drug-serum protein binding shift and its implications on predicting drug clearance and drug-drug interactions. ISSX Workshop: Translating Preclinical Data to Human Clearance and Pharmacokinetics; 2016 Oct 27-28; Boston, MA.

Address correspondence to: Dr. Yurong Lai, Drug Metabolism, Gilead Sciences Inc., 333 Lakeside Dr., Foster City, CA 94404. E-mail: yurong.lai@gilead.com; or Dr. Xiaomin Liang, Drug Metabolism, Gilead Sciences Inc., 333 Lakeside Dr., Foster City, CA 94404. E-mail: Xiaomin.Liang@gilead.com 